\title{
Analysis on the Competitiveness of Social E-Commerce Firms under the COVID-19-a Case Study of Jingxi
}

\author{
Ran $\mathrm{Jia}^{1,{ }^{\dagger}}$ Shuangyuchen $\mathrm{Li}^{2,}{ }^{\dagger}$, and Zeyao $\mathrm{Li}^{3,}{ }^{*},{ }^{\dagger}$ \\ ${ }^{1}$ Department of International Business, Liaoning Normal University, Liaoning, China \\ ${ }^{2}$ Department of Economic, Xi'an Jiaotong-Liverpool University, Jiangsu, China \\ ${ }^{3}$ Department of Finance Management, Central South University, Changsha, China \\ *Corresponding author: 8102191220@csu.edu.cn \\ 'These authors contributed equally.
}

\begin{abstract}
In recent years, the outbreak of COVID-19 has affected economic development as well as people's daily life. In this background, the Internet economy has become a hot topic worth people's attention. The outbreak has weakened the real economy but boosted online business. This paper mainly uses Porter's Five Forces Model and obtains data from Jingdong financial statements and other websites to make a detailed analysis of Jingxi's competitiveness. Also, in order to obtain more realistic first-hand data, we surveyed and recorded the prices of products on the Jingxi platform over a one-week period and compared them with competitors' platforms. From the research results, Jingxi has a high competitiveness, can stand out in many industry competitors, and has a splendid development prospect. This paper will not only fill a gap in the relatively little research on Jingxi, but will also provide reference and lessons for the future path of e-commerce.
\end{abstract}

Keywords: COVID-19, Jingxi, Michael Porter's Five Forces Model, social e-commerce

\section{Introduction}

A sudden outbreak of the epidemic has severely impacted the world, affecting all aspects of the economy and society. During the pandemic, the service sector has been greatly negatively affected. The difficult environment for manufacturing is largely downstream and gradually upward. Much the same is true in other industries. The epidemic will also significantly affect China's export trade, further exacerbating the difficulties of many downstream enterprises in China, and gradually spreading to upstream and middle enterprises. However, some new businesses are quietly emerging, and some enterprises are rapidly transforming. One typical phenomenon is the rapid increase of online business. In the process of epidemic prevention and control, Internet platforms have played a positive role. As the peak of the epidemic fades away, numerous Internet platforms continue to expand, which leads to the competitiveness of enterprises continues to increase. In this case, shopping e-commerce leads a sudden rise, and $\mathrm{O} 2 \mathrm{O}$ model hold decline. Conversely, new retail and community group buying has been given a new mission.

Ran Jia. Author is with Liaoning Normal University, Dalian, Liaoning 116000 China. She is now with the Department of International Business. (Email: 1337891276@qq.com).

Shuangyuchen Li. Author is with Xi'an Jiaotong-Liverpool University, Suzhou, Jiangsu 215127 China. She is now with the Department of Economic. (Email: $460952117 @$ qq.com).

Zeyao Li. Author is with Central South University, Changsha, Hunan 410000 China. She is now with the Department of Finance Management. (Email: 8102191220@csu.edu.cn).

In order to further study how China's new online Internet platforms improve their competitiveness to deal with this crisis, domestic and foreign literature has high reference value. In the existing literature, there is no lack of discussion and research on China's shopping social e-commerce industry platform. Li states that online consumption in China has declined significantly due to COVID-19. New businesses need to recover [1]. According to Jia et al., in recent years, the number of consumers on taobao, Jingdong, Vipshop and other traditional mainstream e-commerce platforms tends to be stable, while the growth rate of users is gradually slowing down [2]. However, Chinese social 
consumption has diversified characteristics, and the consumption of sunken market is large, which provides a consumer base for social e-commerce [3]. Therefore, if China's social e-commerce platforms want to improve their competitiveness, it is necessary to pay attention to the feelings of users in sunken market. Taking Pinduoduo, a well-known platform in the sector, as an example, Deng finds that Pinduoduo has achieved great success because it sees the consumer potential of the sunken market and sells low-priced products that target the needs of sunken market users [4]. In addition, ecommerce Industry Snapshot reports that Pinduoduo is challenging Alibaba to regain control of valuable data on parcel whereabouts and improve its e-commerce shipping tracking system [5]. Wang also used Porter's five Forces model to conduct a detailed analysis of Pinduoduo [6]. However, in the context of globalization, market demand has changed, which provides latecomers with opportunities to enter the market [7].

Combined with the above analysis we can find, Jingxi, the social e-commerce platform launched by Jingdong in 2019, has stood out in recent years for its impressive performance and unique model, and is of great research value. However, unlike other social platforms such as Pinduoduo, little research has been conducted on Jingxi.

In summary, this paper uses Jingxi as the subject of this study to explore Jingxi's level of competition in the shopping e-commerce space. Furthermore, how to promote the competitiveness of Jingxi can also be covered. This paper can fill the gap in the relatively little research that has been done on Jingxi, and at the same time provide reference for the development of e-commerce innovation.

\section{Data and method}

\subsection{Data}

Jingxi, formerly known as Jingdongpingou, officially changed its name to Jingxi in 2019, separating from Jingdong and becoming an independent social e-commerce platform. The business form is like Pinduoduo, with Pinduoduo as its main business. It was once known as JD's version of Pinduoduo. But Jingxi uses the gold brand of Jingdong accumulated over the years, shouted low not low-quality slogan. Compared with the prevalence of fake goods, Pinduoduo formed its own unique advantages. At present, Jingxi has established in-depth cooperation with 200 industrial belts across the country. With direct supply from the 'factory + direct' hair from the origin as the featured product model, it has built a bridge between low-price good goods and consumers, and provided one-stop ecommerce solutions for farm, factory, and foreign trade merchants. Since its launch in September 2019, Jingxi e-commerce has rapidly covered 100,000 factories and tens of thousands of farms and has sold more than 1 million tons of agricultural products and 7 billion factory products, reaching more than 1 billion users. Jingxi takes the value proposition of 'saving new life' and aims to become the preferred platform for people's life consumption.

\section{2 method}

In qualitative research, this paper uses Porter's five Forces model to analyze the competitiveness of Jingxi. Porter's Five Forces model was proposed by Michael Porter in the early 1980s. He believes that there are five forces that determine the scale and degree of competition in the industry, which together affect the attractiveness of the industry and the competitive strategy decisions of existing enterprises. The five forces are the bargaining power of suppliers, the bargaining power of buyers, the entry ability of potential competitors, the substitution ability of substitutes, and the competitiveness of existing competitors. To make this section more informative, Porter's article will be referred to and used in the following content [8].

First of all, the bargaining power of suppliers refers to the ability of suppliers to obtain a better price when existing enterprises purchase raw materials from them. Suppliers affect the profitability and product competitiveness of existing enterprises in the industry mainly through their ability to raise the price of input factors and reduce the quality of unit value. The bargaining power of the buyer refers to the ability of the buyer to profit from the opposition between the seller and the bidder by 
means of competition such as lowering the price, demanding higher product quality or demanding more service items. In addition, the threat of new entrants refers to the threat posed by new entrants to existing enterprises in an industry. On the one hand, the entry of some new enterprises brings new production capacity and new resources to the market, but on the other hand, they may seize the existing raw materials and market share and intensify competition. For existing enterprises, the entry of new enterprises will affect the level of profitability, which will reduce the level of profitability and even cause losses, and seriously or even crisis the survival of these enterprises. The entry possibility of potential entrants is determined by the entry barrier. Among them, the barriers to entry mainly include economies of scale, product differences, capital requirements, conversion costs and other aspects, some of which are difficult to break through by means of replication or imitation. Similarly, the threat of substitution refers to the fact that some businesses in two different industries can offer goods and services that may be substitutes for existing businesses. These goods and services can also meet consumer demand to some extent, and are even better and cheaper. The competitiveness of existing competitors is based on the threat of existing enterprises in the industry to the enterprise itself. Most of the companies in the industry, mutual interests are closely linked, as part of the enterprise overall strategy of the enterprise competition strategy, the goal is to make my own business relative to the competition advantage, therefore, is the inevitable result in the implementation of the phenomenon of conflict and confrontation, these conflicts and confrontation, make up the existing competition among enterprises. Competition between existing enterprises is often reflected in price, advertising, product introduction, after-sales service and other aspects.

\section{Results and Discussion}

\subsection{Bargaining power of suppliers}

(1) Degree of supplier concentration, product price and quality assurance.

Supplier bargaining power refers to the ability of suppliers to obtain a better price when existing enterprises purchase raw materials from suppliers. Jingxi has adopted S2B2C, a new e-commerce marketing model that integrates suppliers with distributors and serves customers together. Large suppliers at the S-end can effectively solve the problem of low supply concentration and scarce stores with high quality production capacity. As a large supplier, the S-end can screen out excellent suppliers for the centralized procurement of tens of thousands or even billions of channels. Jingxi has its own supply chain of origin, providing direct quality products for the factory without any middlemen to earn price difference. The platform has certified the factory as a real one and passed third-party quality inspection. Therefore, it has a better price advantage in terms of purchasing goods from suppliers. At the same time, selected quality suppliers will provide relatively high quality products as agreed.

(2) Whether the supplier is the core customer group, and whether the supplier can easily transfer to new customers.

In terms of $\mathrm{O} 2 \mathrm{O}$ fresh business involved in Jingxi, community residents are the core customer group of fresh industry. Fresh food is sold in large quantities all the year round as a necessary food for people's life. S2B2C mode makes commodity prices lower, which is relatively attractive to customers. At the same time, Jingdong will continue to guide the flow of customers to Jingxi platform for a long time, and the customers sent to Jingxi platform will produce certain stickiness to the platform after a consumption. Data show that nearly $70 \%$ of new users enter the platform with shopping needs, and the unique "buy cash back" launched by Jingxi not only meets the needs of shopping, but also gives consumers a good sense of experience. On November 11, 2020 (2020.10.2111.11), the 7-day repurchase rate driven by Cash rebate of Jingxi is as high as $80 \%$, and the App channel rate of the next day return visit rate of old users is as high as $90 \%$. Jingxi can better lock in the traffic brought by Jingdong. The support of large volume of traffic is the profit password of ecommerce, so suppliers will not easily choose to transfer to new customers. 


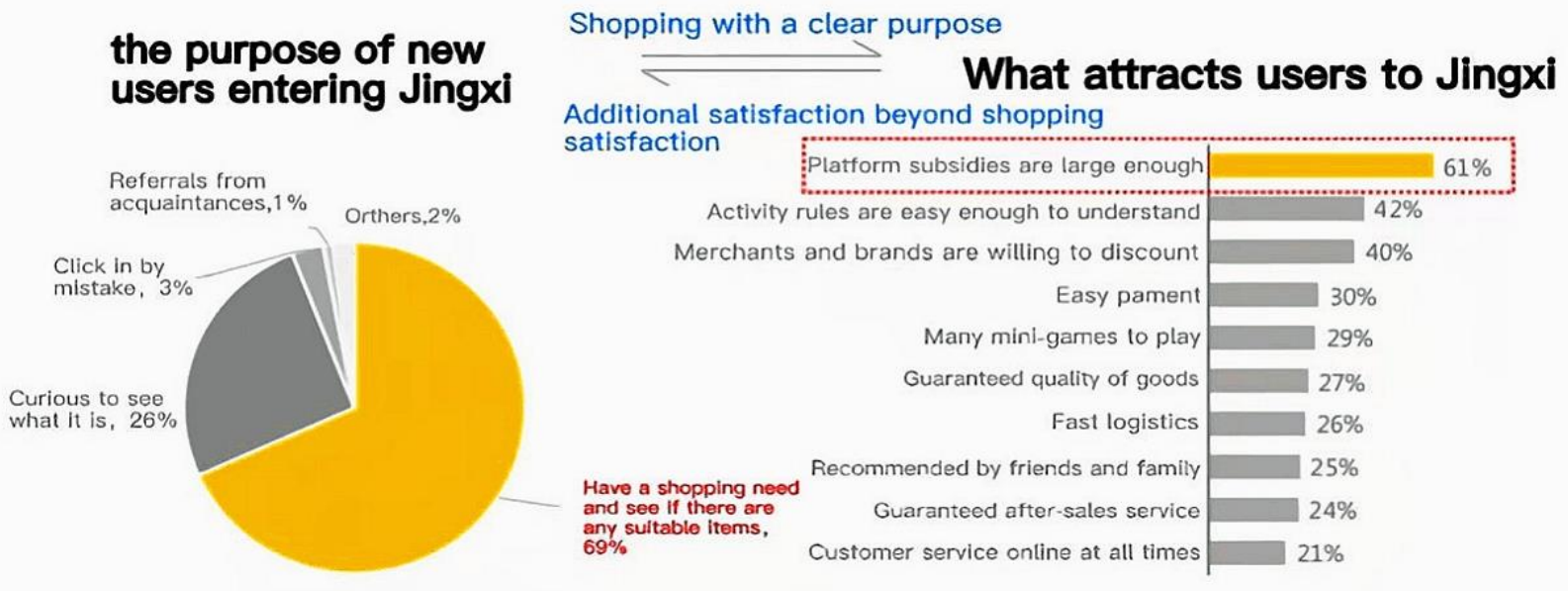

Figure 1. Scale of sinking market

Data source: Aladdin Data Assistant, Ebon Power Research Institute, 2020 Sinking Market consumer Research

\subsection{Buyer bargaining power}

After analysis, Jingxi's buyers are in a favorable position and have strong bargaining power. Buyer bargaining power refers to the buyer's ability to profit from the seller's position against the seller's competitors by using competitive means such as lowering prices, demanding higher quality products or asking for more services, which is also known as the buyer's ability to bargain. The bargaining power of Jing xi's purchasers is analyzed in three specific ways.

(1) The concentration of buyers or the size of business volume

Jingxi's target customer group is in the sink market: As shown in Figure 1-2, the sink market is defined as cities, counties and rural areas below the third tier, including approximately 200 prefecturelevel cities, 3,000 counties and 40,000 townships. The most distinctive feature of this market is its vast size, its large and dispersed population. Therefore the concentration of buyers of Jingxi is low.

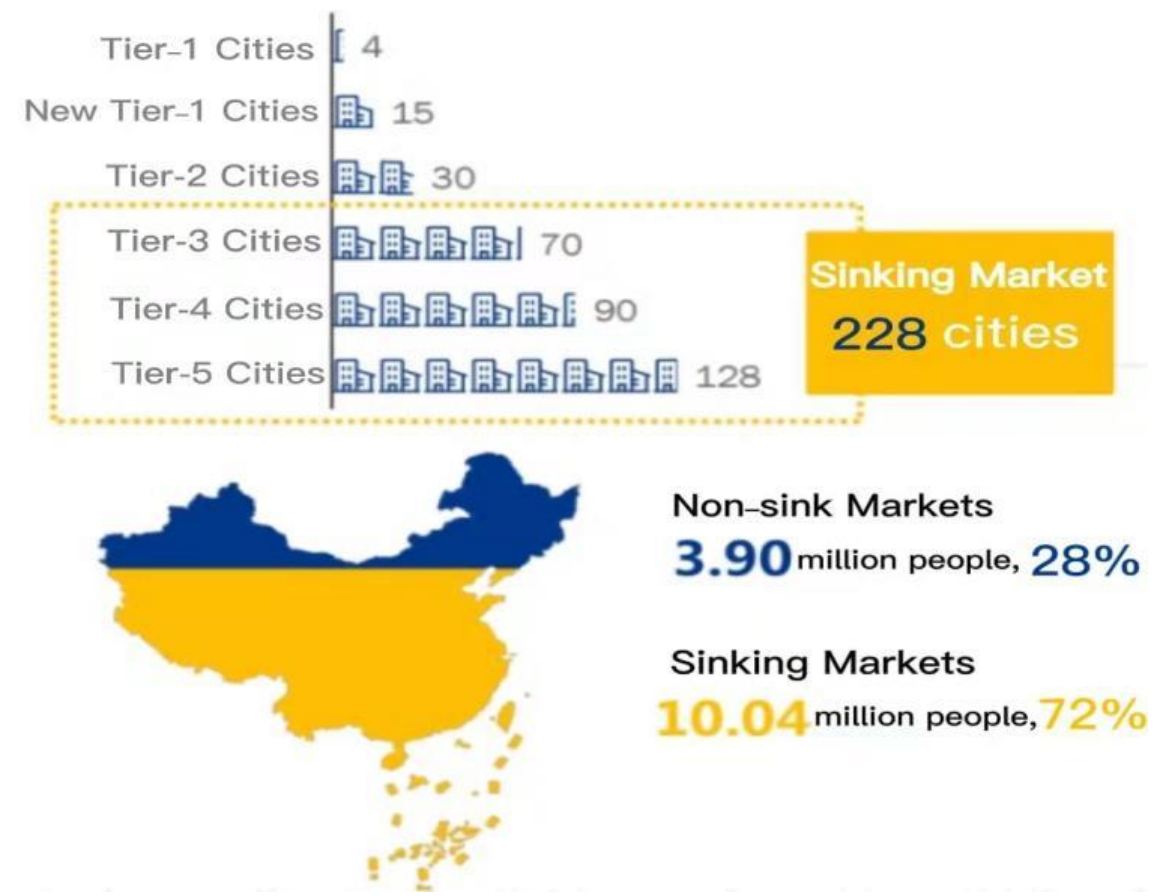

Figure 2. Sinking market scale map 
Data source: First Financial, New First Tier Cities Institute, 2020 City Business Attractiveness Ranking.

National Bureau of Statistics, The 2018 Census.

Ministry of Commerce, China E-Commerce Development Report 2019

The user profile of consumers in the sunken market has the characteristics of low income $(58 \%$ of people with a monthly income of less than RMB 6,000), price sensitivity, socialization with acquaintances and a lot of leisure time.They are basically individual consumers who buy fewer goods with low prices for single items. As a result, the business volume that can be created per unit consumer is small and individual consumption behavior cannot pose a threat to Jingxi. In this respect, the bargaining power of the purchaser is weak.

(2) Degree of product differentiation

The e-commerce industry in China is now well developed and the market is becoming saturated. As a result, intense competition inevitably leads to a high degree of homogenization. Jingxi's products are not very differentiated in terms of price and quality from those of its competitors Pinduoduo, Meituan Youxuan and Xingsheng Youxuan. There is a high degree of substitutability of goods in these platforms so the bargaining power of buyers is strong in terms of products.

(3) Degree of information mastery

With online shopping being basically transparent, and with so many e-commerce platforms, it is not costly in terms of time and energy for consumers to compare products and services. In other words, the switching costs are very low and therefore buyers have full choice. If products and services do not meet expectations and prices are not attractive enough, consumers will easily switch platforms. It is difficult for suppliers to gain consumer loyalty.

In summary, Jingxi, jist like other e-commerce platforms, is a business dominated by online purchasers, who have strong bargaining power.

\subsection{Threat capacity of new entrants}

The threat of new entrants has modest impact on Jingxi, which is mainly related to the high entry barrier in purchase e-commerce field. There are two main factors that affect the entry barrier of the online shopping e-commerce. One is the brand preference of users and the other is the switching cost. First of all, according to Luo (2020), Jingxi is a new social e-commerce platform created by Jingdong to enter the sinking market, with six mobile terminal channels including wechat and QQ, two hundred-million-level platforms, supported by Jingdong and Tencent[7]. Jingxi can fully enjoy the number of users accumulated on Jingdong and Tencent platforms, so users have a certain brand preference for Jingxi. Second, as for conversion cost, there are two aspects that can be analyzed, which are buyers and sellers respectively. Switching costs refer to the one-time costs incurred when an individual switches from one provider of a product or service to another. This kind of cost is not only economic, but also time, energy and emotion. For buyers, for example, due to incompatibility between Apple's ios and Android operating systems, if a long-time Apple user switch the phone to a Huawei phone, there may be a high switching cost. However, it is different for online shopping field. Buyers can transfer from one online shopping platform to another online shopping platform without paying high switching costs. It also provides new company a chance to enter. From the sellers' view, the situation of new entrants is opposite. If the seller wants to change the platform to sell goods, it needs to pay high switching cost, such as economic cost and time cost. For three consecutive years, the market growth rate of social e-commerce has shown a declining trend, and social dividends are being continuously divided up [9]. The enterprises that have entered are unwilling to give up the dividends they enjoy, and the new entrants are striving to enter this field to share the benefits. Therefore, it also raises the barriers to entry in the field of shopping e-commerce. To sum up, the new entrants impose tiny threat to Jingxi. Nevertheless, as a new entrant in the field of shopping ecommerce in recent years, Jingxi still needs to tense potential entrants to improve its competitiveness. 


\subsection{Substitution capacity of alternatives}

The substitute is also less of menace to Jingxi. There are two main substitutes of Jingxi. One is ebusiness platforms focus on online shopping, such as Taobao and Tmall. The other is the offline entity store platform. In order to obtain more authentic and reliable data, we chose Taobao and Wal-Mart as representatives, and recorded the prices of the same goods on these three platforms in a table within a week. According to the results, Jingxi's products have lower prices and higher praise rates. Hence, Jingxi has truly achieved 'low price not low quality, and attracted a large number of customers. As is reported by Jingdong 's 2019 performance, nearly $40 \%$ of new users on Jingdong website came from Jingxi during the "Double 11" period, and more than $70 \%$ of new users in the fourth quarter came from third-tier to sixth-tier cities. The consumers targeted at Jingxi have low per capita income and consumption level, so Jingxi may become their first choice for shopping consumption. Zhang (2020) has found that that Jingxi is committed to focusing on industrial belts and creating direct and excellent products, which attracts more manufacturers to settle in Jingxi [10]. In order to enable more users to purchase direct superior products from the factory, Jingxi has continuously expanded its multi-faceted live streaming services, such as live streaming offline to stores, factories and parks, to help consumers better understand products. In addition, Zhang also argues that the time-effectiveness promotion plan of ' 1,000 counties and 10,000 towns within 24 hours' proposed by Jingdong logistics also helps Jingxi to further establish logistics advantages and reduce the threat of substitutes, especially offline substitutes. The "24-hour delivery in ten thousand counties and ten thousand towns" time acceleration program aims to improve the efficiency of delivery in sunken markets, and is expected to achieve "24-hour delivery" in these regions by 2020 [10]. Compared with the two to three days it generally takes for express delivery in low-line cities, these plans can improve the consumer experience and further reduce the threat of substitute.

\subsection{Competitiveness of existing competitors}

It is known that in China's trillion level fresh market, fresh line penetration rate is very low due to fresh timeliness, high requirements of cold chain, high hierarchy and high transportation cost. There is still a broad market space to be explored, especially the sinking market. The epidemic as a catalyst, but also for the development of online fresh industry. Internet companies are keen to grab a slice of the market, but many of the smaller players don't have an edge. At present, the industry giants are about the following three echelons. The daily orders of Meituan Preferred and Duoduo Shopping platform have exceeded 25 million, ranking first. The daily single volume of Orange heart optimization, Xingsheng optimization and Shihui group is about 10 million, belonging to the second echelon; Ali's Hema bazaar, with a unit volume of around 3 million, is in the third tier. The existing market share is concentrated in a small number of companies with similar strength and more companies in the early stage of development, fierce competition but there are still business opportunities to be explored.We use Table 1 to compare the main competitors in the social commerce industry. 
Table 1. Competitive Comparison of Social E-commerce

\begin{tabular}{|c|c|c|c|c|c|}
\hline $\begin{array}{c}\text { Social } \\
\text { E- } \\
\text { commerce } \\
\end{array}$ & JingXi & $\begin{array}{l}\text { MeiTuan } \\
\text { Youxuan }\end{array}$ & $\begin{array}{l}\text { PinDuo } \\
\text { Duo }\end{array}$ & $\begin{array}{l}\text { XingSheng } \\
\text { YouXuan }\end{array}$ & $\begin{array}{l}\text { ChengXin } \\
\text { YouXuan }\end{array}$ \\
\hline $\begin{array}{c}\text { Establishe } \\
\text { d }\end{array}$ & 2019 & 2020 & 2015 & 2017 & 2020 \\
\hline SKU & $1000+$ & $1500+$ & $1000+$ & $1200+$ & $1500+$ \\
\hline Strategy & $\begin{array}{l}\text { 1.Tencent+Jingd } \\
\text { ong traffic } \\
\text { support } \\
\text { 2.Low product } \\
\text { price not low } \\
\text { quality } \\
\text { 3.Searching for } \\
\text { qual } \\
\text { ity industrial } \\
\text { zones } \\
\text { 4.S3B2B"direct } \\
\text { link" model } \\
\text { 5.Rely on } \\
\text { Jingdong supply } \\
\text { chain }\end{array}$ & $\begin{array}{l}\text { 1. Group } \\
\text { leadership } \\
\text { centricity } \\
\text { strategy } \\
\text { 2. Takeaway } \\
\text { business } \\
\text { builds up } \\
\text { rich business } \\
\text { development } \\
\text { capability } \\
\text { 3. } \\
\text { Community } \\
\text { group buying } \\
\text { with } \\
\text { dedicated } \\
\text { staff and } \\
\text { clear rewards } \\
\text { and } \\
\text { penalties. }\end{array}$ & $\begin{array}{l}\text { 1. First } \\
\text { mover in } \\
\text { the sink } \\
\text { market with } \\
\text { strong user } \\
\text { stickiness } \\
\text { 2. Agricult } \\
\text { ural e- } \\
\text { comme } \\
\text {-rce } \\
\text { experience, } \\
\text { innate } \\
\text { advantages } \\
\text { in the field } \\
\text { of fresh } \\
\text { cost }\end{array}$ & $\begin{array}{l}\text { 1. WeChat } \\
\text { customer } \\
\text { acquisition,redu } \\
\text { ce the cost of } \\
\text { traffic spending; } \\
\text { 2.Transformatio } \\
\text { n of small } \\
\text { community } \\
\text { shops into user } \\
\text { pick-up points } \\
\text { to reduce } \\
\text { delivery cost } \\
\text { 3.Three-tier } \\
\text { logistics } \\
\text { system: the } \\
\text { original "pre- } \\
\text { sale + pick-up" } \\
\text { model enhances } \\
\text { delivery } \\
\text { efficiency }\end{array}$ & $\begin{array}{l}\text { 1.Launch of the } \\
\text { Orange Heart } \\
\text { Small Shop } \\
\text { strategy(renova } \\
\text { tion of old } \\
\text { community } \\
\text { shops) and } \\
\text { implementation } \\
\text { of the Head of } \\
\text { Mission } \\
\text { Support } \\
\text { Programme } \\
\text { 2.The main } \\
\text { focus is on } \\
\text { fresh } \\
\text { ingredients to } \\
\text { create a full } \\
\text { category } \\
\text { structure }\end{array}$ \\
\hline $\begin{array}{l}\text { Warehousi } \\
\text { ng \& } \\
\text { Logistics }\end{array}$ & $\begin{array}{l}\text { Jingdong } \\
\text { logistics is the } \\
\text { main focus, } \\
\text { supplemented } \\
\text { by third party } \\
\text { logistics }\end{array}$ & $\begin{array}{l}\text { The industry } \\
\text { leader in the } \\
\text { number of } \\
\text { grid } \\
\text { positions }\end{array}$ & $\begin{array}{c}\text { Localised } \\
\text { grid ware } \\
\text {-house } \\
\text { constructio } \\
\text { n. }\end{array}$ & $\begin{array}{l}\text { Self-built three- } \\
\text { tier logis } \\
\text {-tics: } \\
\text { city (central } \\
\text { warehouse)"- } \\
\text { street/township( } \\
\text { grid } \\
\text { warehouse)- } \\
\text { community/vill } \\
\text { age shop (pick- } \\
\text { up point) }\end{array}$ & $\begin{array}{c}\text { The grid station } \\
\text { serves as a } \\
\text { transit station } \\
\text { connecting the } \\
\text { main } \\
\text { warehouse with } \\
\text { the offline shop } \\
\text { pick-up points, } \\
\text { creating an } \\
\text { itegrate } \\
\text {-d model of } \\
\text { sales and } \\
\text { distribution, } \\
\text { and cold chain } \\
\text { integration }\end{array}$ \\
\hline $\begin{array}{c}\text { Traffic } \\
\text { sources }\end{array}$ & $\begin{array}{c}\text { Jingdong, Wecha } \\
\mathrm{t}\end{array}$ & $\begin{array}{c}\text { Meituan,Wec } \\
\text { hat }\end{array}$ & $\begin{array}{c}\text { Advertising } \\
\text { Weibo }\end{array}$ & Wechat & $\begin{array}{l}\text { Group leader } \\
\text { ground, } \\
\text { WeChat, } \\
\text { Dropshipping }\end{array}$ \\
\hline $\begin{array}{c}\text { Average } \\
\text { daily } \\
\text { order } \\
\text { volume }\end{array}$ & $700 w$ & $2000 w$ & $10000 \mathrm{w}$ & $800 w$ & $1700 w$ \\
\hline
\end{tabular}


Based on Table 1 we provide a brief overview of Jingxi's competitors:

(1) MeiTuanYouXuan: The entrance is located in the most prominent place of Meituan APP, providing meituan optimization with an excellent basis for user traffic conversion. However, compared with Duoomai, Meituan's sinking market has less natural flow, so it needs to consume more costs and operating expenses in the process of acquiring customers and user operation.

(2) PinDuoDuo: Pinduoduo has a natural advantage in user recognition by virtue of its traffic in the sinking market. However, there are major problems in operation, which will have an impact on users' subsequent consumption experience and partners' willingness to cooperate.

(4) XingShengYouXuan: 'pre-sale + self-lift' leading enterprises, a large number of offline stores, retail experience in the sinking market. But the original community group buying platform, flow capital is easy to be limited.

(5) ChengXinYouXuan: Didi platform as the logistics foundation, leading capacity scheduling ability, and has flow support, and the leader of the incentive system is good, drainage effect is significant. However, the establishment time is short, the retail experience is insufficient, and the supply chain foundation is weak.

Compared to these existing competitors, Jingxi has the following innovative competencies:

Unlike the B2C model of traditional e-commerce, Jingxi has adopted the S2B2C model, using this "direct chain" model to integrate every role: from sourcing, pricing system to packaging and shipping, from sales and marketing support, logistics to after-sales service and various industry information.

In response to the escalating consumption in the sinking market and the pursuit of higher quality goods and services, Jingxi has deepened the industrial belt at the S-side to create factory-quality direct products, forming a unique product value. In addition, Jingxi has joined hands with local governments to reach industry-specific cooperation, attracting small and medium-sized factories to Jingxi [9]. The C2M (Customer Directly Connected to Manufacturing) light incubation model was chosen to directly connect consumers with manufacturers. This not only eliminates the need for inventory, logistics, distribution and general sales, saving intermediate costs and allowing consumers to get high quality products at ultra-low prices, but also increases the visibility and brand value of local industrial and agricultural brands, enables the digital transformation and upgrading of industrial zones, promotes the employment of local talents and contributes to the high quality development of local economies. Through the "direct chain" model, Jingxi benefits both the S-side (supply) and the C-side (demand), giving social and economic value to Jingxi products.

At the same time, Jingxi has created a new marketing model by building a pan-entertainment experience for social shopping. In addition to the tens of billions of subsidies from various social ecommerce companies and cash-back games, Jingxi has also taken the lead in launching the industry's unique "cash-back shopping" scheme. In addition to the various social e-commerce subsidies, game cashback and other subsidy models, Jingxi also took the lead in launching the industry's unique "shopping rebate", which offers real money and direct profits to provide consumers with a sense of "cost-effective and satisfactory" consumption; in response to the habit of sinking users who love to brush videos and watch live broadcasts, Jingxi innovatively opened a traceable live broadcast, which helps consumers directly know good products through live broadcasts of offline factories, enhancing the interactive effect of shopping and creating a richer and more diversified social shopping experience. The most important thing is that Jingxi has entered into a partnership with Tencent, and in 2019, the first level of WeChat will be fully launched on Jingxi, so that consumers can get a lot of traffic through the first level of WeChat Tab, allowing them to enjoy both social and shopping.

\section{Conclusion}

The purpose of this paper is to use the Porter's Five Forces model, a tool for analyzing the competitiveness of companies, to analyze the competitiveness of Jingxi in the marketplace, and to provide reflections and reference for the development of social e-commerce and even the e-commerce industry as a whole. As a result of the analysis in this paper, we believe that overall Jingxi has a strong 
competitive position. In terms of bargaining power of suppliers, Jingxi has a high concentration of purchases and has its own supply chain of origin, while Jingdong gives flow and supply channels to support, the bargaining power of suppliers is low; from the perspective of bargaining power of buyers, the user group is located in a sink market with a large and scattered population, with a low concentration of business and low bargaining power; from the perspective of threat of new entrants, Jingxi has a low bargaining power. In terms of the threat of new entrants, the e-commerce sector has high entry barriers in terms of financial support, traffic flow and brand building, and the threat of new entrants has little impact on Jingxi due to its reliance on the e-commerce giant Jingdong. In terms of the competitiveness of existing competitors, the S2B2C model that Jingxi pioneered has unique product value, user service value, social value and marketing value that enable it to gain a foothold in the highly competitive e-commerce space. These strengths are what make Jingxi stand out in the face of fierce competition.

However, through the analysis in this paper, Jingxi also faces some great challenges. The conversion cost of users on social e-commerce platforms is not high, and the business is still dominated by online buyers; competitors such as Pinduoduo and Meituan Youxuan are equally strong in terms of user volume, traffic and operational experience. And with the development of the sinking market, the growth of social e-commerce dividends is gradually slowing down, and the collocation market is starting to appear to be saturated. The competition in the social commerce space will continue to heat up. Other social e-commerce players such as Pinduoduo are facing the same challenges. Based on this, we have given some suggestions for the development of the social ecommerce sector: Firstly, social e-commerce companies should pay attention to differentiation strategies and create platform features. The various social e-commerce platforms in the market all use subsidy strategies and advertising to attract consumers, which has a certain propaganda effect, but it is not the core competitiveness of the platform, and sometimes excessive propaganda can be counterproductive. The platform should form a competitive advantage by innovating its own business model. Secondly, the collocation-type social e-commerce should strengthen product quality control. The phenomenon of difficult to guarantee the quality of goods is common in social e-commerce. The social platform should pay attention to the quality of goods from the source, storage, packaging, transportation, after-sales and other aspects, and improve the threshold for merchants to enter. Third, collocation-type social e-commerce should seize customer demand and bind customers in depth. The platform should strengthen the investigation of consumers' willingness to buy and use, create a truly beneficial and convenient sales network, improve user stickiness, enhance user stickiness and overcome the problem of low conversion cost of buyers' platform.

In summary, this paper uses the Porter's Five Forces model to analyze Jingxi's competitive capabilities, which theoretically fills a research gap in the academic field on this emerging social ecommerce platform, and enriches the practical application of the Porter's Five Forces model in the analysis of corporate competitiveness. In reality, this paper clearly confirms that Jingxi has greater competitiveness and development potential in the e-commerce sector, which can provide investors and industry analysts with some reference when making investment decisions and value judgments about Jingxi. As one of the e-commerce platforms, the strengths and weaknesses of Jingxi's business model can be used as a reference for other platforms to improve and innovate, thus promoting a more orderly and dynamic development of the whole e-commerce industry.

\section{Reference}

[1] Li Xiaoyang. (2020). Festival Therapy. Beijing Review, 63(27), 32-33

[2] Jia Lingling, Liu Qin \& Liu Shuai. (2021). The Analysis of Social Group-buying E-commerce Industry Based on SCP Pattern and Development Suggestions. ECONOMIC RESEARCH GUIDE (16),137-139. doi: CNKI: SUN: JJYD.0.2021-16-044.

[3] Honghua Chen, Shuwei Zang, Jin Chen, Wentian He \& Hang Chang Chieh (2020) Looking for meaningful disruptive innovation: counterattack from Pinduoduo, Asian Journal of Technology Innovation, DOI: 10.1080/19761597.2020.1820352 
[4] Deng Yaqing. (2018). Growing Pains. Beijing Review, 61(32), 36-37.

[5] E-commerce upstart wants its data back from Alibaba. (2019). FRPT - Ecommerce Snapshot, 5-6.

[6] Wang Yi. (2019). Poundland's e-commerce platform based on Porter's five forces model Competitive Environment Analysis. Modern Trade Industry (30),51-52. doi: 10.19311/j.cnki.1672-3198.2019.30.023.

[7] Cao, E., \& Li, H. (2020). Group buying and consumer referral on a social network. Electronic Commerce Research, 20(1), 21-52. https://doi-org.ez.xjtlu.edu.cn/10.1007/s10660-019-09357-4

[8] Porter, M. E. (2008). The Five Competitive Forces That Shape Strategy. Harvard Business Review, 86(1), 78-93.

[9] Luo Mengyao. (2020).An analysis of social e-commerce Jingxi's marketing strategy. National Distribution Economy(33),21-23. doi:10.16834/j.cnki.issn1009-5292.2020.33.007

[10] Zhang Jing. (2020). Jingdong weaves a network of sunken markets: goods + field + logistics. Mordern Advertising (13),32-33. doi: CNKI: SUN: XIGU.0.2020-13-015. 